\title{
TEACHING NON-INDIGENOUS SPEAKERS OF ISIXHOSA: A CRITICAL EVALUATION OF OWN PRACTICE
}

\author{
Phumla Kese \\ Stellenbosch University
}

\begin{abstract}
In this article, the author reports on a mid-year critical evaluation of her teaching practice at a multilingual university with students who are non-indigenous speakers of isiXhosa. Data is gleaned from participatory observations, critical-incident journal entries, students' assessments, views of an outside observer, and student feedback.

The conclusion is drawn that to achieve communicative competence in the Xhosa language, the following are vital towards meeting the challenges of students' anxieties about the course: increasing student motivation, confronting the differences between students' home languages and isiXhosa, using tutors who are proficient in the students' mother tongue, as well as encouraging creativity together by keeping a balance between oral and written tasks.
\end{abstract}

\section{Keywords}

critical evaluation; third language learning; additional language (AL); student feedback.

\section{BACKGROUND}

As a lecturer and home language speaker of isiXhosa at a historically Afrikaans University, I realised very early in my teaching career that frequent reflection on my own and the students' experiences of IsiXhosa Communication, a third-year module, is necessary to keep the module relevant. A clash of interests regarding the language of instruction and related pedagogical challenges is not uncommon in multilingual learning contexts. In this article, I draw on pedagogical encounters in a class consisting of two groups of students: (1) a minority group of non-Afrikaans-speaking students who prefer English as a medium of instruction, and (2) a majority group of Afrikaans mother tongue (MT) students accustomed to learning and being taught in Afrikaans. What both groups have in common is a lack of previous exposure to isiXhosa and an anxiety about their ability to meet the demands of the IsiXhosa Communication course. Having a stronger command of English than of Afrikaans, I soon recognised a crucial need for a frequent evaluation of my teaching practice to meet them halfway by devising language usage practices that suited everyone in class. The fact that the students and I (the lecturer) do not share a mother tongue or culture is generally viewed as a disadvantage in the light of teaching. In spite of the fact that I have a better command of English, which happens to be a home language of the minority, it was necessary to ensure that students remained motivated to learn isiXhosa by acknowledging their home languages.

In recognition of the importance of including evaluation in the curriculum plan, the need to pursue formative evaluation accelerated after noticing mounting worries about how different the isiXhosa linguistic structure is to the students' language repertoire. An additional concern 
was their inadequate exposure to isiXhosa as sufficient exposure remains a requirement for successful learning of a new language (Ringbom \& Jarvis, 2007:106; Willis \& Willis, 2007:217).

The evaluation research is done with students who are future teachers at primary or secondary schools.

\section{PURPOSE}

\section{Evaluation objectives}

This report mainly aims at

- creating and increasing motivation to learn isiXhosa by the students;

- improving quality of my teaching practice by identifying growth areas;

- discovering what is valued and students find worth or merit in; and

- maximising learning of isiXhosa as a third/fourth language to enable the students to communicate in school contexts and in social settings.

\section{Key evaluation questions}

The evaluation initiative, purpose and process were sufficiently discussed with the students, whom I view as key participants of this evaluation research, and the formulation of the following evaluation questions is adapted from Mezirow's (1997) transformative theory:

- What can be done to stimulate and sustain motivation of the students to learn isiXhosa?

- What are students' perceptions of the teaching methods applied in relation to effective learning of isiXhosa as an Additional Language (AL)?

- How has the curriculum linked course objectives with students' language usage needs and the context of learning? (Ross, 2006: 756)

- What can be done to improve the teaching practice of isiXhosa Communication to non-indigenous speakers?

\section{DRAWING ON THE CONTEXT}

In South Africa today, there is a growing demand for university graduates to speak the local languages dominant in their provinces, which directs the context of learning, in this regard, towards schools where the current teacher-education students are likely to work. IsiXhosa is one of the national official languages, and yet most students in this particular university class perceive it rather as a foreign language because of the difference in physical locations, social spaces, culture and ethnicity between themselves and the people who speak it. In this article, I put language teaching into context, where it is not limited to the boundaries of the lecture theatre. The discussions and conclusions made are drawn from observations made when extending learning into settings beyond the classroom and taking into consideration the language used in the anticipated world of work. The context of learning is viewed as crucial in making decisions about what to teach and about what the nature of assessment should be, in line with the ultimate aim of the isiXhosa course: preparation for workplace eventualities, as highlighted in Visser and Venter (2004:43). The curriculum for IsiXhosa Communication is developed in such a way that the context of learning is three-fold, namely, 
- the university classroom;

- outside the classroom/in the streets, not just the physical space of the classroom, as Young (2009) suggested in his notes about the practice theory; and

- in schools where students practise teaching, as guided by the course module. This includes cultural insight as well as communicating with other stakeholders such as the parents, teachers and the learners inside and outside the classroom -- be it in the sports fields or during class intervals or in meetings.

\section{LITERATURE REVIEW}

\section{Critical evaluation theory}

In terms of the critical evaluation theory, evaluation is perceived as an essential part of the educational process for local quality improvement and it also gives an indication of the degree to which students' learning objectives are being met and whether teaching standards are being maintained (Ross, 2006:756). Kreber and Cranton (2000:477) pointed out that critical evaluation of teaching practice is evidence of merit in instruction that is equated with the scholarship of teaching.

\section{Mezirow's transformative theory}

Even though this manuscript reports on the reflection of my practice, I decided to intensify the evaluation by including students' views so that I can do the evaluative reflection with them. This theory suggests that feedback from students who are willing participants can lead to effective content-knowledge acquisition activities, positive transformation, as well as increased motivation to learn. Mezirow (1997) adds by stating that lessons learnt from the reflective evaluation project, which he refers to as 'transformational learning' ought to cause a change in thinking after processing information. In other words, findings should be practically instrumental in implementing change for the betterment of teaching and learning practices. This means that reflection should be about the course content and the method, not only of the educator but also of the target students.

\section{Teaching and learning strategies}

\section{Motivation}

Motivation is crucial to new language acquisition, and an ability to motivate learners is a teaching advantage for effective learning because when students are stimulated, they are likely to perform tasks in pursuit of outcomes (Brown, 1994: 261; Van Avermaet et al., 2006: 175; Willis \& Willis, 2007:3). Hofer (2002:120) maintained that tertiary students who are intrinsically motivated are more likely to successfully use cognitive strategies such as elaboration and organisation, resulting in deeper processing of the material. He further suggested that extrinsic rewards are most beneficial when they contain informative feedback that contains specific directions for change and that focus on improvement.

\section{Getting students to reflect on how they learn}

It has become common for students learning isiXhosa as third or even fourth language (L3/L4) to rely on copious note-taking and being bombarded with new words that are easily 
forgotten before meaningful use. This is often coupled only with written assessments, to the neglect of adequate tuition for the development of oral production. With the awareness of the distinctions between second language, third language, and foreign language learning and acquisition (Kilfoil \& Van der Walt, 2007:6; Ringbom \& Jarvis, 2007), my evaluation is mindful of the languages that are dominant and the prevailing multilingual face of the classroom. Hofer (2002:121) recommended that lecturers should think about their instructional methods and professional relations with their students, recognise their students' need for self-determination, and provide opportunities for meeting social goals in ways that are compatible with academic goals. My own research (Kese, 2003:88) reinforces this by suggesting that educators within higher education should study the learning habits and tactics of their students in order to increase teaching capacity.

\section{A need to acknowledge the difference in linguistic form and use it favourably}

While acknowledging the extensive scholarship suggesting that cross-linguistic similarities play a positive role in language learning and that learners look out for similarities to their own languages when they learn a new language, a new provision has to be made on what to do when such similarities are minimal, as in the case of comparing Afrikaans/English to isiXhosa. Ringbom and Jarvis (2007:145-7) argued that linguistic differences may cause more difficulties for the learner and that perception (not comprehension) is of importance. I contest this argument by saying that linguistic differences may not cause problems with learning of some languages, but this depends on the teaching approach and attitude towards such differences. In the case of learning isiXhosa AL, the undisputable differences between isiXhosa and Afrikaans/English (languages most familiar to the students) can be an advantageous starting point in language teaching and learning and present fewer chances for similarity-related confusions at later stages of learning. This implies that acting on the major linguistic differences right from the onset can be a foundation on which confidence to construct error-free simple sentences/phrases can be built. My assertion is that isiXhosa is an African language with a lot of influence from the KhoiSan language and culture (Gxilishe, 2004: 3; Maylam, 1972; Peires, 1981; Tyrell, 1976), such as the rattling in clicks, onomatopoeic expressions and a strong link between proverbs and metaphoric expressions, with the culture of amaXhosa (the Xhosa people). For this reason, strategies and linguistic rules for learning isiXhosa are, to a certain extent, distinct from those for European languages. An Afrikaans-speaking learner cannot be expected to use exactly the same strategies in learning isiXhosa as a second AL as he/she employed when learning English as a first AL. With this understanding, one can deduce that isiXhosa grammatical form and other technical language aspects draw on the Xhosa culture. Therefore, noticing these structural differences from the beginning could also help in doing self- or peer-assessment/correction until the students reach automaticity in learning for independent and accurate production.

Jessner (2009:39) suggested that helping the learners acquire strategies to compare languages, to transfer and to infer has benefits in regard to language acquisition and that strategies applied by the more successful students may be learnt by those who are less successful (Griffiths \& Parr, 2001:249). The principles for L3 or second AL teaching and learning cannot be generalised across all languages; even though some approaches are universally successful in application, it cannot be taken for granted that what works in an individual context of practice would do for the other. 


\section{Fusion of language and culture}

The essence of language is meaning (Brown, 1994:70). If that is so, no language learning is meaningful nor complete without tapping into the culture of the native speakers. JordanJackson and Davids (2005:251) argued that the best source of information about another ethnic group is experience. Jessner (2008:249) elaborated on this by saying that acquiring a new language means a lot more than the manipulation of syntax and lexicon. She further noted that culture classes have a humanising and motivating effect on the language learner and the learning process. They help learners observe similarities and differences among various cultural groups; hence, teaching language is also teaching culture. A fusion of culture into language classes improves one's understanding of the language as well as the people who speak it, and cultural competence falls in the category of the pragmatic aspect of communicative competence (Jessner, 2008:78-80).

\section{METHODOLOGY}

\section{Evaluation approach}

With the belief that all teachers are on a learning journey, Mezirow's (1991) model of reflection is adapted to analyse data in three categories, namely, the content, the process and the premise. This means that the evaluation would be based on the sufficiency of content knowledge that I want to facilitate, the process involved in helping the students learn and the context or frame of reference for which I base the suitability of the pedagogical approaches applied. This is blended with the literature base drawn from the theory of transformative learning.

\section{Sampling}

A total of 147 students participated in this evaluation research: 66 Foundation Phase and 81 Intermediate/Senior Phase teacher-trainees. It is important that not all the students completed the evaluation tasks assigned to everyone else. For instance, all Intermediate/Senior Phase students completed questionnaires, while both groups participated in plenary discussions.

\section{Sources of data}

The selection of data collection instruments is confirmed by Dee Fink's (1999) proposal for techniques for Evaluating Your own Teaching Practice, in which he strongly recommended five major sources of data, namely, self-monitoring, audio-tape/video, information from students in the form of questionnaires and oral interviews, students' test results, and outside observers. I used all of the above methods except the audio-tape/video.

\section{Student feedback}

The validity and reliability of student feedback as a source of evidence is a subject of heated controversy among academics, especially when the report has some weighting towards performance appraisal. However, it is, despite scepticism regarding its value, still an essential component of any module or course offered within any faculty (Berk, 2005:55). To avoid fallacious and invalid criticisms, I made sure that the students were clear about the purpose of 
the evaluation and tried to get as close to their 'true' responses as possible, as Wei and Moyer (2009:164) suggested.

\section{Reflection essays, structured questionnaires and plenary discussions}

These three instruments closely complemented each other. Students wrote reflection essays at the end of the first semester, focusing on what motivated them to learn and what pedagogical methods worked or did not work well. To supplement that, structured questionnaires were designed to quantify and identify patterns in responses so that the short answers could validate class discussions. Anonymity was ensured in all the evaluation proceedings.

\section{Field notes/Critical incidents}

Field notes were succinctly jotted down as dated critical incidents and clear transactions in the lecturer's reflection book/teaching journal immediately after marking assessments and giving constructive plenary feedback. Some were elicited in class and randomly beyond the classroom as a result of continuous reflection on my practice/prolonged active involvement in the teaching and learning process as an on-going participant observer.

\section{Assessment grades}

A variety of task scores were viewed to evaluate performance during lecture and tutorial sessions in the form of written tasks and role-plays respectively.

\section{Inviting a lecture analyst from the university's Centre for Teaching \& Learning}

An outside observer from the university's Centre for Teaching \& Learning (CTL) was invited to my class.

\section{Ethics}

Evaluation and research are similar activities; however, they have important differences. The former does not usually require ethics committee approval (Morrison, 2005:285). Nevertheless, I felt it necessary to get formal consent from the students who were key participants in this evaluation project and consent forms were signed. An oral feedback was given to the students upon completion.

\section{Method of analysis and interpretation}

To analyse and interpret data, reference to relevant literature on third language teaching and learning as well as critical evaluation is made. In addition, a sound theoretical base pertaining to the transformative learning theory is employed. 


\section{PRESENTATION OF RESULTS AND INTERPRETATION}

\section{Success indicators}

\section{Merging language and culture}

Because of the very close link between the Xhosa language and the culture of the indigenous speakers, I decided to confront the students with the realities of cultural practices in schools so they would not only be aware of cultural norms but also analyse the activites and thus become conscious of the effects of culture on learning activities. In addition, opportunities to compare their respective cultures were created to embrace socio-cultural difference. Examples of typical realities include a scenario with a Senior Phase class, consisting of teenagers/adolescents, an age group in which most boys and girls go for initiation. Teachers need to realise that an 'ikrwala' (a graduate from an initiation institution into manhood/ a newly initiated man) will change his learning behaviour and/or conduct at school. Fellow learners will call him 'Bro' or 'Boeter' (both terms are examples of slang used by the Xhosas) or 'Bhuti', meaning 'big brother'. This practice is complemented by a formal dress code for the 'new young man' in nude colours such as grey, beige, brown, mixed with coffee-coloured clothes and a matching cap/hat; some even carry a rod around for a certain period. They wear the costume for a prescribed period of time. Permission to put on the ikrwala costume instead of the school uniform depends on individual school policies. In addition, the mere fact that the Xhosa culture is characterised by respect might either positively or negatively affect group learning in the sense that the boys who have not been initiated would submit to the ikrwala and there are chances that the ikrwala might abuse the cultural status by bullying girls and boys who have not gone through the initiation process yet. On the contrary, this cultural practice (ulwaluko) is traditionally intended to groom a man's character and make him a socially responsible adult. At times, the ikrwala will come one or two weeks after the schools have re-opened, which might be a drawback to his studies, giving the teachers/tutors/academic mentors a duty to help him catch up with the work that he has missed while still attending the initiation school.

Another significant cultural aspect that captured the students' interest was the notion of politeness. The students saw value in the unit on 'making polite requests' and they successfully linked it up with the culture of the native speakers, for whom respect is a prominent moral virtue.

\section{Assessment highlights}

One of the processes that helped the students settle in well was starting with the less challenging and gradually proceeding to more demanding tasks. Making use of a dummy test lowered the anxieties connected to the fear of uncertainty about what to expect and what not, including my assessment style. Students insisted on the supply of the previous year's end-ofthe-year test paper, along with the memo, but I refused to give them a written memo. I told them to rather go through the question paper together with me in class so that they could participate in the sense-making of the expected answers and independently construct authentic dialogues rather than be given prescribed dialogues for them to memorise in a mimic fashion. Persuading them to listen actively and participate in the meaningful construction of the memo, instead of spoon feeding them with a readymade memo, helped them remember the answers in the dummy test that they had written. It was also a way of encouraging them to see value in class attendance instead of posting less meaningful answers on WebCT. What was important 
for me was to get them to understand the assessment rubric so that they could aim to achieve high performance according to stipulated criteria for attaining high marks, which was a major incentive to them. I found that a brief discussion on how marks would be allocated for any task can be rewarding for the students.

Regarding the development of learning journals, most students found the task challenging, claiming that the tempo at which the Xhosas speak outside the classroom was fast and made it difficult to figure out what was said and they thus ended up losing the gist of the conversations. This claim is a possibly well grounded; however, one of the goals for the exercise was to have them exposed to such voice intonations and become acquainted with the Xhosa speakers' social communicative tendencies, such as exclamations, laughter, silences, clapping of hands and the use of contractions which characterise the manner in which they converse among each other right on the site where the language is alive! Therefore, it was actually an achievement to let them observe aspects such as the use of contractions that make the speakers sound fast. For instance, in Xhosa, one word can make a full sentence, while the same word can be expressed in three/four/five words in English or Afrikaans. However, the one-word sentence can be divided into different language aspects when broken down. A good example of a contraction would be: 'Sobonana' meaning 'See you!' or 'Bye!' derived from 'Siza kubonana' (Ons sal mekaar sien. /(We'll see each other) used to conclude a conversation. Another example is that of this popular commanding phrase: 'Yiza apha!.' (Kom hier!)/ (Come here!) which contracts into 'Yiz'apha!' and sounds like 'Yizapha!.'

Pertaining to the content and method/process of teaching and learning, adequate time was spent on the introduction to the course in such a way that topics were discussed with the students prior to the actual intensive teaching to negotiate meaning in the course outline. They appreciated being given a chance to select themes and topics that they found most relevant to their potential world of work. I remained firm with other themes that I felt were necessary, regardless of their respective choices. Examples are the National Anthem, Children's Rights Charter and Class Management, with the latter bearing aspects such as ice-breakers, energisers to use with learners for respective age groups, teaching mathematical literacy, giving instructions/commands, making polite requests, writing notices or letters to parents/guardians, written interviews with parents and children, sympathy cards, get-wellsoon cards, drawing up an agenda for a meeting with parents, invitations to concerts or fundraising events, congratulatory cards, and other expressions of good wishes through cards, in-person and by sms's.

Trainees were given teaching and learning opportunities for giving constructive feedback on test scripts (individually) and orally in plenary sessions. This was done in a sensitive manner to avoid lowering the students' motivation levels. Red ink was not used, but rather a pencil or a different-coloured ink, and the use of a cross (' $\mathrm{X}$ ') was not applied. Instead, underlining the incorrect phrase/spelling/grammar was done and then accurate answers/comments were written along the margin or on top of the phrase or word that was not appropriate. his encouraged learners to value corrective feedback and helped when doing revision. One student commented,

Fills out feedback on each test - so helpful when learning and found the songs very stimulating and increasing the vocabulary.

[Citations from students are direct and no alterations, corrections or editing of grammatical errors are made.] 
I discovered that it is better to be more specific and not leave any information gap when giving instructions on translation questions. To avoid confusion, I found it best to state if I expected the students to give word-for-word translation or a sensible translation into Afrikaans or English. For instance, when I require the students to give literal or word-forword translation, without worrying whether the sentence makes sense or not, for a sentence such as, 'Uza kufika nini?', the literal translation into Afrikaans/English would be 'Jy sal arriver wanneer?'/'You will to arrive when?', whereas a sensible translation would be 'Wanneer gaan jy arriver?'/ When are you going to arrive?'

\section{Materials}

Students found the translation of print into both English and Afrikaans to cater equally for language needs of the entire class in the sense that neither Afrikaans nor English students felt left out or less important in the multilingual classroom, in which most students were Afrikaans MT and some had a better command of English than of Afrikaans. The viewing time was saved for those students who were only looking for the colour that represented their preferred language as each language had a different colour on the overhead projector (OHP) transparencies, as Van der Walt et al. (2001:123) suggested. This made it easy for these students to know exactly where to direct their eyes. For those students who were willing to view all three languages, this technique had an academic gain as it gave them an opportunity to increase semantic capacity while processing the information. In addition, it improved their active reading skills even though preparation was quite labour-intensive for me as I sometimes had to consult with a colleague to verify translation before taking texts to class. I used PowerPoint very minimally as it was not always appropriate for interactive tasks, in which case the traditional board and chalk facilitation method worked well. Nevertheless, presenting information in students' most familiar languages, or 'co-languaging' in the words of Garcia (2009: 209), made students feel respected and took away a sense of alienation for those who were possibly concerned about under utilisation of their languages

\section{Class interaction}

Students were encouraged to participate in class and given time to ask questions, but explanation time in lectures was not always enough. However, they had tutorials in which to experience more interaction, and both lecture and tutorial attendance was excellent, even for the late afternoon class that ended at $16 \mathrm{~h} 50$. They were also allowed to switch over to either English or Afrikaans in explaining themselves or when finding it necessary. In this regard, Van der Walt (2009:31) has suggested that responsible and occasional switching to the mother tongue while producing one's own constructions should be acknowledged as a powerful resource when used sensibly in leaning spaces. In fact, most students indicated that they first write their dialogues in the languages they are most proficient in and then translate into Xhosa and later write the text over and rehearse speaking it until they attain automaticity.

\section{Tutorials}

Using fully bilingual Afrikaans mother-tongue tutors was a major success as it made up for the lecturer's better command in English and gave all the students an opportunity to ask questions in the language with which they are most familiar. By so doing, I made sure that no language group felt alienated. One student commented that, 
Tutorials gave us more opportunities to speak because the class was smaller; then you don't need to be shy. Singing was awesome; this motivates me.

In all, tutorials were vibrant and very effective because of having fewer students per session, grouped according to their language preferences, which prompted the reserved ones to take the risk of speaking in Xhosa and asking questions in front of their peers. Students enjoyed tutorials and the attendance was exceptionally good. Initially, there was going be a mark awarded for tutorial attendance but I found that marking the attendance register was timeconsuming so the weighting for tutorial attendance was waived.

\section{General reception of the course by both Afrikaans and English speaking students.}

It was interesting to note that there are commonalities in the reception of the module. What came over strongly were the lecturer's enthusiasm, energy and words of motivation (Appendix A) that inspired them. The students all indicated that they benefited from group tasks in the form of orally presenting authentic dialogues. In addition, creative exercises such as crossword puzzles developed spelling and the cues also helped them remember meanings of theme-based words. Both English- and Afrikaans-speaking students found the translation of task instructions and phrases led to the simultaneous development of their languages. The songs kept them motivated and helped in the retention of acquired information. They also indicated that they received a firm grounding for further continuation with isiXhosa classes. Students commented,

Songs and melodies helped us to remember and learn which we can do with the learners in schools

\section{I found the songs to be helpful in motivating me to learn the Xhosa language $:$}

The Afrikaans-speaking students related more to most of the commonly used Anglicised nouns because of the sound and grammatical technicalities that are similar. Both isiXhosa and Afrikaans apply a similar principle of affixing the diminutive element to the end of the noun; ' $a n a$ ' in Xhosa and ' $t j i e$ ' or ' $i e$ ' in Afrikaans. Table 1 illustrates similarities between isiXhosa and Afrikaans:

Links between isiXhosa and Afrikaans diminutive formation

\begin{tabular}{|l|l|l|l|}
\hline Anglicised word & in English & Diminutive & in English \\
\hline ifestile ('n venster) & a window & ifestilana ('n venstertjie) & a small window \\
\hline itafile ('n tafel) & a table & itafilana ('n tafeltjie) & a small table \\
\hline isikolo (;n skool) & a school & isikolwana ('n skooltjie) & a small school \\
\hline
\end{tabular}

\section{Dealing with students' common errors}

Through a critical pedagogical reflection, Afrikaans- and English-speaking students experience phonological and morphological/syntactical errors when learning isiXhosa just as Xhosa speaking students do when they learn English or Afrikaans. I was conscious of the language profile of my students and also had the advantage of understanding the two most prominent languages of the class population, despite having a better command of English. With this, I discovered most common spelling errors arise from phonological differences 
between Afrikaans, English and isiXhosa. What I found to work well was asking them to form study problem-solving groups, where the students engaged in

- sharing their test scripts or assignment scripts as they have valuable individualised feedback which helps them identify the patterns of corrective feedback/comments regarding certain aspects of the language; and

- sharing their learning strategies, what works well from them, what helps them to acquire the language and master it through exchange of meaning.

Examples of students' language usage in written and oral tasks, in the form of assignments, class tests and dialogues/role-plays, follow:

\section{(a) Written}

- Ndicela ooxolo' instead of writing 'Ndicela uxolo.' The 'u' sound erroneously leads to the writing of the English 'oo' sound as in cool, pool, mood, soon, moon, tool, and so on. instead of the Xhosa ' $u$ '.

- 'Umqueta' instead of 'umkhwetha'. The 'khw' sound in Xhosa is a 'q' sound as in 'question' in English.

- 'Ujaqonda?' instead of 'Uyaqonda?' The ' $\mathbf{y}$ ' sounds like ' $\mathbf{j}$ ' for ' $\mathbf{j a}$ ' in Afrikaans instead of sounding like ' $y$ ' for 'yellow' in English.

- In composed written dialogues, they would say, 'Molweni abafundi.' (Good morning/Good day learners) instead of writing 'Molweni bafundi.' This shows a tendency to forget to leave out the first vowel of the noun when addressing a person/people at second level, which is a crucial and basic grammatical rule in isiXhosa that applies in greetings and other communicative scenarios.

- 'Ndifilile' instead of 'Ndiphilile' because the 'ph' sounds like 'f' for 'fish' in Xhosa.

- 'Kuyachisa namhlanje' instead of 'Kuyatshisa namhlanje' (It is extremely hot today/It is burning today.), because the 'ch' for 'church' in English is spelt as 'tsh' in Xhosa.

\section{(b) Spoken}

- At the beginning of the course, most students erroneously pronounced 'Xhosa' as 'Khosa'. The 'Xh' was produced in such a way that it sounded like the 'c' for call in English. This confirms the importance of starting with drillings in clicks and challenging phonics right from the beginning so that their confidence can be boosted before they start to produce longer texts.

- Again, confusing the written spelling as well as pronunciation/verbal utterance of ' $\mathbf{j}$ ' and ' $y$ ' was sometimes a mistake, as explained above. A concern lies in the fact that when ' $\mathbf{y}$ ' is preceded by ' $\mathbf{n}$ ' (as in 'nest' in English), it produces a sound that is often used to formulate vulgar language or teasing words. $(\mathrm{n}+\mathrm{y}=n y)$. Examples of syllables are ny $+\mathrm{a}=n y a$. So when a learner of isiXhosa makes an error or mistake in pronouncing ' $\mathbf{j}$ ' (as in ' $\mathbf{j a m}$ ' in English) instead of ' $\mathbf{y}$ ' (as in 'yellow'), it can be perceived as rude/vulgar or rather just strong language. For instance, when singing the song 'Iphi inja yam encinane?' meaning 'Where is my baby/little dog'/Where is my puppy? The 'inja' (a dog) can mean something else when written or sounding as 'inya'. The list goes on with all other syllables such as 'nye, nyi, nyo' and 'nyu'. It is therefore necessary to sensitise students about cautious use of these consonants. Applying clear corrective feedback helps in dealing with such errors and mistakes. 


\section{(c) Cross-linguistic errors}

It was interesting to find out how language patterns can erroneously be transferred by some Afrikaans speaking students by applying their first language grammatical principles to a second language (English) and then to a third language (isiXhosa)

- 'The learners is ... ' instead of saying 'The learners $\underline{\text { are }}$

- 'The Xhosa people was ...' instead of saying 'The Xhosa people were ...'

- 'Songs is awesome' instead of saying 'Songs are awesome'

I think this is because in Afrikaans, one would say 'Die leerders is ...' as 'is' remains the same even in plural form; hence, this internalised knowledge translates into an error when applied in a language with different rules/principles.

\section{What needs a revisit/did not go well}

Prescribing the use of journals as part of continuous assessment generally did not work well because, I deduced, the critical incidents were faked and not real. As a result of intensive reflection on this matter, I decided that language learning log books could be regarded as a viable option.

\section{Rapport}

Becoming transparent, approachable, available for consultation, and yet firm improved relations in class even though I was still not satisfied with how certain groups of students related to each other. Time was unfortunately against allowing me to address such behaviour. Pertaining to unacceptable classroom behaviour, I managed to address such conduct, and the guilty student would generally stop immediately or apologise in class or after class through an e-mail. I must say that the level of co-operation was not at the same level between the groups in the Foundation Phase and those in the Intermediate/Senior Phase; meaning that the profile of the students, such as their field of expertise, can influence their attitudes towards how we teach and to a great extent feed into relevant pedagogies.

I took advantage of the Xhosa cultural value assigned to names of people or a name given to a newborn baby, with the understanding that Xhosa learners feel good when a teacher calls them by their first names when facilitating learning or communicating with them. I thought it was necessary for the pre-service teachers to understand the meanings of the names of their prospective learners. I gave a student in one of the classes a Xhosa name and called him 'Vuyo', meaning 'Joy' or 'Happy'. In a section of an assessment that was intended to check understanding of the meanings of modern Xhosa names, $100 \%$ of the students in Vuyo's class got it right, while a few from the other class forgot the meaning even though they had the explanation in their course manual. This could be an effective approach to improving lecturerstudent rapport as well as building vocabulary in a less demanding way, but only for small groups rather than big classes.

\section{Constructive criticism}

\section{Approach}

The students indicated that they could have gained more confidence in the production of texts if there was not so much focus on fluency over grammatical accuracy. I actually planned to 
put more emphasis on form and accuracy in the second semester as I observed that it was necessary to get the production of texts flowing first. Although intensive orals were done in class, in tutorials and in assessments, most students felt that there should still be more oral assessments than written as they believe it is not about how well you write but how well you can speak the language. However, a few were more interested in spelling exercises.

\section{Framework}

Students' comments show their dependence on rigid frameworks (quoted verbatim): Ifelt that isiXhosa module did not provide a concrete framework because some of the work was not in the prescribed manual, instead notes were issued in bits.

The course outline was tempered with.

In response to the above evaluative statements, the approach in question works for those who think being given manageable bits of notes helps rather than getting a huge stack that makes one lazy and bored without even trying. However, even though it was only a few who felt that way, the criticism seemed valid to me so I decided to revisit the framework for the future. Regarding 'tampering with the course outline', there was a list of themes or communication topics to be covered, but the class was asked if they had any special interests or themes that were not among the list that could be integrated. We then reached a mutual consensus as to which ones to prioritise, which could be realistically covered within a few months of contact lectures. Most of them found this approach exciting, while a very few found it strange and unstructured to include them in the planning of the teaching and learning outline.

\section{Lessons learnt from an outside observer}

The following clip serves to give an idea of the feedback of an outside observer from the university's CTL:

\begin{tabular}{|l|l|l|l|l}
\hline $\begin{array}{l}\text { 2010/02/22 } \\
\text { Report } \\
\text { sumitted at am. }\end{array}$ & $\begin{array}{l}\text { Phumla has a gift of teaching, for motivating students and her passion for the } \\
\text { language and for her students show. I actually learnt a few things in Xhosa and } \\
\text { felt like I would join her classes and learn more Xhosa; She moves from the } \\
\text { overhead projector to the board in a seamless manner; The exercise with } \\
\text { scenario-based phrase matching strips translated into both English and Afrikaans } \\
\text { was brilliant; The interaction with students on questions/answers/corrective } \\
\text { feedback on the black board was very good and the synthesis of the lesson was } \\
\text { brilliant, a bit rushed. The silence worked to reprimand a distracting student and } \\
\text { she ended up stopping what she was doing without being pointed or shouted at. } \\
\text { However, she should ensure that everyone has a copy of the handouts for a class } \\
\text { activity before she gives out instructions. Furthermore, it is not advisable to tell } \\
\text { students that there is little time left before the end of the lecture as it is a risk } \\
\text { that some could switch off. She should also try not to rush the } \\
\text { summary/synthesis part of the lecture even if it means carrying over to the next } \\
\text { lecture.' }\end{array}$ \\
\hline
\end{tabular}

The feedback made me feel confident about my teaching and yet realise that even small teaching mistakes can have a negative impact on student learning. For instance, if I decide to 
give students a task within the last 5 minutes of the lecture, it is not necessary to remind them about little time left as that could distract their concentration.

\section{Plea for an extension of hours and stretching course over 3 years.}

Most students felt that isiXhosa Communication should be offered at third- year level and then isiXhosa as a Language of Learning and Teaching (LoLT) be offered in the final year, which is the crucial period to prepare for the undeniable multilingual and multicultural workplace. Because I knew the language was fairly new to them, I supplied them with a book to use as a life-time resource for refreshing their memory even beyond graduation and as a tool to activate new learning.

\section{Constraints}

Situational constraints included

- the set-up of lecture halls with fixed long rows of desks, which made it difficult to do certain interactive exercises; some classes were extremely small for big groups, which became a problem in very hot weather conditions;

- rushed summaries or conclusion for some lectures because students had to leave about 5 minutes earlier to cater for the walking distance to a Sport Science class that was quite far from where the isiXhosa classes were held.

\section{SUGGESTIONS FOR FUTURE IMPLEMENTATION}

The following points should be considered for the development of professional expertise and effective student learning activities:

- Maintaining a balanced scale of 50:50 for both oral and written tasks

- Increasing students' enthusiasm by organising excursions to the real situation, where the Xhosa language and culture are alive, as well as exploring monuments

- Designing assessment tasks that entail striking up a conversation in Xhosa with those who are proficient in the language so that trainees will become aware of the importance of exposure to the language and take steps to increase their exposure to the isiXhosa culture and language because students still need more access to the language apart from their contact with school children during various teaching practice seasons

- Having adequate planning time with the tutors so that they can develop logical and effective ways of facilitating learning. For instance, when helping students understand possessive personal pronouns (izimnini), they can be advised to make use of a related table (see Appendix B) in a manner that will enable them to discover strategies to remember newly introduced information. In the course of learning, the following selfdeveloped model can help students to effectively use the possessive pronoun table in such a way that they can logically

i) Identify the patterns of noun prefixes by noticing which are determiners of appropriate concords (links/matches with) to be prefixed to the stem of the isimnini, that is, a possessive personal pronoun;

ii) Make a list of nouns that they know of and classify them accordingly;

iii) Increase or build vocabulary;

iv) Construct their own authentic sentences using newly acquired words with selected pronouns; 
v) Ask for verification of correctness from tutors or other reliable sources;

vi) Do corrections after verification of their own communicative production to ensure accuracy; and

vii) Use the corrected version orally in a real situation.

\section{CONCLUSION}

Negotiation of meaning about relevance of themes when introducing the course, active listening in class, cautious corrective feedback and constructive criticism by the lecturer, motivating students, and awarding credits for creativity in tasks are all crucial to drive production of intelligible texts in isiXhosa. It was further observed that over-employment of one popular method of facilitation can leave an instructional gap as traditional methods are still relevant and can successfully complement the modern approaches for effective teaching of isiXhosa AL. On that note, 'fancy' teaching styles or immense volumes of knowledge about different approaches to facilitation are not enough without an awareness of the best learning strategies and the worst hindrances to learning the target language, based on a specific student profile, as this would feed into how the students prefer to be taught and on the most successful approaches to assessment. Lecturers should vigorously observe and enquire about how their students learn so that they can adopt teaching methods that are compatible with those learning techniques, in consideration of a unique student profile, including their respective tastes and attitudes. This prompts a need for isiXhosa AL curriculum developers to maintain a fair balance between oral and written tasks for accountable instruction. Furthermore, it can be rewarding to teach culture in context so that students within teacher education can gain a deeper insight into the implications of cultural practices and beliefs in schools.

\section{INTROSPECTIVE VOICE}

This critical evaluation revealed students' perceptions about my practice and helped me to feel the pulse and tone of the classroom community. I have learnt that students' different personalities and attitudes play a vital role in shaping teaching methodologies. As much as I would like to orchestrate my methods in such a way that there is no discord in learning, I find it hard to imagine an 'overarching' tune for a melody that would be in harmony with all the students' individual preferences. While this is so, this evaluation made me confirm the importance of constantly considering the profile of the students and their learning needs in relation to the context of practice.

I must stress that attending the Professional Educators Development for Academics (PREDAC) workshop as part of the Stellenbosch University's CTL programmes gave me the drive to embark on such an intensive evaluation. No matter how uncomfortable evaluation and being evaluated can be, no evaluation of teaching practice is complete without the participation of students because a student is the one who teaches teachers to teach so that they can continuously improve the quality of facilitation.

Having students who obtain high grades does not necessarily or always translate into reasonable competency, which implies that we, as course presenters, need to continuously evaluate our assessment methods/approaches with the view that assessment tools can be 
powerful learning vehicles against set outcomes (Dee Fink, 2003). This insight compelled me to strive to get the spoken productive skills to match up with high assessment grades and yet to develop the students' grammatical accuracy. I found, and still find, it difficult to wrestle with the little time that students spend in the classroom with so much to be done to keep them motivated to learn. For this reason, students of isiXhosa L3 or L4 need to be aware that a lecturer can only do so much and they have a duty to take care of the rest, as summative learning cannot take place inside the lecture theatre only. This would challenge the norm of having students who achieve cum laude in an AL but are hardly able to speak the basics of that language because they are focusing on written assessments and theory but neglect to ensure proficiency in the spoken version. This tradition of imbalance undeniably compromises the integrity of our practice as language practitioners; hence, we need to take steps towards implementing accountable assessment, which is a crucial aspect of effective instruction.

Although I recognise that students' comments can lead to growth in teaching practice, it takes boldness to include them in the evaluation exercise as lecturers are often not given an opportunity to justify their choice to apply unfamiliar approaches. As much as I wanted to find out the truth and obtain sincere expressions, I had to protect myself from emotional harm from insensitive remarks by following an 'outside-insider' strategy to receiving, analysing and interpreting the data. I have learnt that it is almost impossible to satisfy all the individual needs of students, especially in big classes, as they have different personalities, come from different schooling backgrounds, and have different attitudes and diverse learning strategies which define their preferences and tastes as to how their learning should be facilitated. From experience, not all the students see the value or worth when they receive quality tuition so teachers have to be explicit about why they engage students in specific tasks. For instance, pedagogical benefits should be clear in terms of set outcomes and what the relevance of the teaching and learning activities is for reaching such intended results.

\section{RERERENCES}

BERK, A. 2005. Survey of 12 strategies to measure teaching effectiveness. International Journal of Teaching and Learning in Higher Education. 17(1):48-62.

BROWN, HD. 1994. Teaching by principles. An interactive approach to language pedagogy. Upper Saddle River, NJ: Prentice Hall Regents.

DEE FINK, L. 1999. Evaluating your own teaching. In Seldin, P (Eds). Improving College Teaching. Oklahoma City, OK: University of Oklahoma Instructional Development Program.

DEE FINK, L. 2003. Creating significant learning experiences: An integrated approach to designing college courses. Community College Journal. San Fransisco, CA: Jossey-Bass.

GARCIA, O. 2009. Bilingual education in the twenty first century: A global perspective. Chichester, UK: Wiley-Blackwell.

GRIFFITHS, C \& JM PARR. 2001. Language-learning strategies: Theory and perception. ETL Journal. 55(3):247-253.

GXILISHE, S. 2004. The acquisition of clicks by Xhosa-speaking children. Per Linguam. A Journal of Language Learning.. 20(2):1-12.

HOFER, B. 2002. Motivation in the classroom. In Svinicki, M \& W McKeachie 2006 . McKeachie's Teaching Tips. $\left(11^{\text {th }}\right.$ ed). Boston, MA: Houghton Mifflin.

JESSNER, U. 2008. Teaching third languages: Findings, trends and challenges. State of the Art Article, 41(1):15-56. 
JORDAN-JACKSON, FF \& KA DAVIDS. 2005. Men talk: An exploratory study of communication patterns and communication apprehension of black and white males. The Journal of Men's Studies, 3(3):347-367.

KESE, PP. 2003. Improving first-year technikon students' listening practices to promote academic success: A case study. Cape Town, RSA: Peninsula Technikon Theses \& Dissertations. Paper 80 .

KESE, PP. 2010. Umntu ngumntu ngabantu: IsiXhosa: ULwimi lokuFundisa nokuFunda. Taal van onderrig en leer.- Department of Curriculum Studies, Cape Town and Fakulteit van Opvoedkunde, Stellenbosch University. Unpublished course manual.

KILFOIL, WR \& C VAN DER WALT. 2007. Learn 2 Teach: English language teaching in a multilingual context. Pretoria: Van Schaik.

KREBER, C \& PA CRANTON. 2000. Exploring the scholarship of teaching. The Journal of Higher Education, 71(4): 476-496. Accessed 31 Aug 2010 at http://www.informaworld.com/terms-and-onditions-of-access.pdf

MAYLAM, P. 1972. The history of the African people from the early Iron Age to the 1970's. London, UK: Croom Helm.

MEZIROW, J. 1997. Transformative learning: Theory to practice. New Directions for Adult and Continuing Education, 74. Columbia, SC: Jossey-Bass.

PEIRES, JB. 1981. The House of Phalo. A History of the Xhosa people in the days of their independence. Johannesburg, RSA: Ravan Press.

RINGBOM, H. \& S JARVIS. 2007. The importance of cross-linguistic similarity in foreign language learning: Comprehension, learning and production. Clevedon, UK: Multilingual Matters.

TYRELL, B. 1976. Tribal peoples of Southern Africa. Cape Town, RSA: Books of Africa.

VAN AVERMAET, P, M COPLIN, K VAN GORP, N BOGAERT \& K VAN DEN BRANDEN. 2006. Task-based language education: From theory to practice. Cambridge, UK: Cambridge University Press.

VAN DER WALT, C. 2009. The functions of code switching in English language learning classes. Per Linguam, a Journal of Language Learning, 25(1):30-43.

VAN DER WALT, CR MABULE \& JJ DE BEER. 2001. Letting the L1 in by the back door: Code switching and translation in science, mathematics and biology classes. SAALT Journal. 35(2\&3):170-181.

VISSER, M \& E VENTER. 2004. Genre analysis and task-based course design for isiXhosa second language teaching in local government contexts. Per Linguam, A Journal of Language Learning, 20(1):36-56.

WEI, L \& G MOYER. 2009. Resources for research on bilingualism and multilingualism. Oxford, UK: John Willey \& Sons.

WILLIS, D \& J WILLIS. 2007. Doing task-based teaching. Oxford, UK: Oxford University Press.

YOUNG, RF. 2009. Discursive practice in language learning and teaching. Chichester, UK: WileyBlackwell.

\section{BIOGRAPHICAL NOTE}

Phumla Kese facilitates learning of different isiXhosa modules at the Department of Curriculum Studies in Stellenbosch University. She also served at other universities specialising in Teaching Literacy, English Second Language Teaching and Teaching Practice. Her research interests are teaching in multicultural classrooms, academic literacy, parent support regarding helping their kids with literacy tasks, curriculum design and development for language teaching and acknowledgement of slang as a language variety. e-mail address: phumla@sun.ac.za 


\section{APPENDIX A: Word of motivation to teacher trainees}

\begin{tabular}{|l|}
\hline $\begin{array}{l}\text { Teaching is planting a seed, } \\
\text { diligently nurturing the sprouts, } \\
\text { community shares the harvest }\end{array}$ \\
For an ordinary teacher \\
is just a means to earn a living \\
For a responsible educator \\
is yet a service through which \\
a wealth of meticulous graduates is produced.
\end{tabular}

\section{APPENDIX B：Possessive personal pronoun table (Itafile yezimnini)}

Note: Nouns are classified according to their respective prefixes and each prefix influences the concord for each possessive personal pronoun. All the prefix syllables that are in brackets indicate that the particular syllable is silent/passive and only shows off when used in a sentence or phrase. The stems for possessive pronouns in the following table are only for $1^{\text {st }}$ level address:

-am (my) at $1^{\text {st }}$ person; $\quad-$ akho (your) at $2^{\text {nd }}$ person $\quad \& \quad-$ akhe $($ his $/$ her $)$ at $3^{\text {rd }}$ person

\begin{tabular}{|c|c|c|c|}
\hline Noun example(s) & $\begin{array}{l}\text { Noun } \\
\text { prefix }\end{array}$ & $\begin{array}{l}\text { Possessive } \\
\text { pronoun } \\
\text { concord }\end{array}$ & $\begin{array}{l}\text { Possessive } \\
\text { pronoun 'my' } \\
\text { in singular } \\
-a m \text { is the stem }\end{array}$ \\
\hline $\begin{array}{l}\text { umpheki (a cook); umntu (a person); umfundi (a learner/ a } \\
\text { student); umfundisi (a church pastor/ minister); umchweli } \\
\text { (a capenter); umakhi (a builder) [This class has to do with } \\
\text { human beings only and the prefix for plural is 'aba', 'abe' } \\
\& \text { 'ab'] }\end{array}$ & um & $\mathrm{w}$ & $\mathrm{w}+\mathrm{am}=\mathrm{wam}$ \\
\hline $\begin{array}{l}\text { abapheki (cooks); abantu (persons); abafundi (learners/ } \\
\text { students); abefundisi (pastors/Ministers of Religion); } \\
\text { abachweli (capenters); abakhi (builders) }\end{array}$ & $\begin{array}{c}\mathrm{aba} / \\
\mathrm{ab}\end{array}$ & $\mathrm{b}$ & $\mathrm{b}+\mathrm{am}=\mathrm{bam}$ \\
\hline umama ( a mother); umalusi (a shepherd) & $\mathrm{u}$ & $\mathrm{w}$ & $\mathrm{w}+\mathrm{am}=\mathrm{wam}$ \\
\hline oomama (mothers/mums); abelusi (shepherds) & oo & $\mathrm{b}$ & $\mathrm{b}+\mathrm{am}=\mathrm{wam}$ \\
\hline $\begin{array}{l}\text { umlomo; umqolo; umthi; umthombo (a fountain); umlambo } \\
\text { (a river); umoya (wind/ a spirit); umzamo (an attempt); } \\
\text { umqombothi (an African sorghum beer). [This class has } \\
\text { prefix 'um' but does not refer to humans and the prefix for } \\
\text { plural is 'imi'] }\end{array}$ & um & $\mathrm{w}$ & $\mathrm{w}+\mathrm{am}=\mathrm{wam}$ \\
\hline $\begin{array}{l}\text { imiqolo; imithi; imimoya (spirits); imithombo (fountains); } \\
\text { imilambo (rivers); imizamo (attempts) }\end{array}$ & imi & $\mathrm{y}$ & $y+a m=y a m$ \\
\hline $\begin{array}{l}\text { igama ( } \text { a name); ilanga (sun or can mean a day in some } \\
\text { contexts); igqabi; iliso/ imehlo; idolo; ihashe ( } a \text { horse) }\end{array}$ & i(li)/ il & 1 & $1+\mathrm{am}=\mathrm{lam}$ \\
\hline
\end{tabular}




\begin{tabular}{|c|c|c|c|}
\hline amagama (names) & ama & $\mathrm{w}$ & $\mathrm{w}+\mathrm{am}=\mathrm{wam}$ \\
\hline $\begin{array}{l}\text { isifundo (a lesson); isikolo (a school); isitya (a dish); } \\
\text { isimilo (a behaviour); isimemo (an invitation) }\end{array}$ & isi & $\mathrm{s}$ & $\mathrm{s}+\mathrm{am}=\mathrm{sam}$ \\
\hline $\begin{array}{l}\text { izifundo (lessons); izikolo (schools); izitya; izimemo } \\
\text { [All the nouns with 'is' or 'isi' as a prefix in singular would } \\
\text { take 'iz' or 'izi' as prefixes in plural.] }\end{array}$ & izi & $\mathrm{z}$ & $\mathrm{z}+\mathrm{am}=\mathrm{zam}$ \\
\hline $\begin{array}{l}\text { intloko; incwadi; inkomo; intsomi; imoto/ inqwelo- } \\
\text { mafutha; intsimbi ( } \text { a iron bell/ an iron) }\end{array}$ & $\mathrm{i}$ & $\mathrm{y}$ & $\mathrm{y}+\mathrm{am}=\mathrm{yam}$ \\
\hline $\begin{array}{l}\text { iintloko (heads); iincwadi (books) } \\
\text { [All nouns starting with prefix 'ii' take 'zi' as a noun } \\
\text { concord and 'z' as a possessive personal pronoun concord] }\end{array}$ & ii(zi) & $\mathrm{Z}$ & $\mathrm{z}+\mathrm{am}=\mathrm{zam}$ \\
\hline $\begin{array}{l}\text { uluvo (an idea); unyawo (a foot); ulusu (a skin); uluntu } \\
\text { (people in general/people at large }) ; \text { uvavanyo }(\text { a test/ an } \\
\text { examination }) ; \text { uhlolo [an assessment or a check up] }\end{array}$ & $\begin{array}{l}\mathrm{ulu} / \mathrm{a} \\
\mathrm{u}(\mathrm{lu})\end{array}$ & lw & $\begin{array}{l}\text { lw }+ \text { am }= \\
\text { lwam }\end{array}$ \\
\hline $\begin{array}{l}\text { Izimvo (ideas/views/perceptions); iinyawo (feet); iimviwo } \\
\text { (examinations) }\end{array}$ & izi/ ii(zi) & $\mathrm{z}$ & $\mathrm{z}+\mathrm{am}=\mathrm{zam}$ \\
\hline $\begin{array}{l}\text { ubuntu (humanity/a spirit of humanness); ubukhulu } \\
\text { (greatness/size); ubulumko (wisdom); ubuhle (beauty) }\end{array}$ & ubu & $\mathrm{b}$ & $\mathrm{b}+-\mathrm{am}=\mathrm{bam}$ \\
\hline u(bu)tywala [alcohol]; ubuhlanti (a kraal) & ubu & $\mathrm{b}$ & $\mathrm{b}+\mathrm{am}=\mathrm{bam}$ \\
\hline $\begin{array}{l}\text { iindywala (different types of alcohol); intlanti (kraals) } \\
\text { [All nouns starting with prefix 'ii' take 'zi' as a noun } \\
\text { concord and 'z' as a possessive personal pronoun concord] }\end{array}$ & ii(zi) & $\mathrm{z}$ & $\mathrm{z}+\mathrm{am}=\mathrm{zam}$ \\
\hline $\begin{array}{l}\text { ukona (sinning/committing a sin); ukunene (right-hand } \\
\text { side); ukutya (food) }\end{array}$ & $\begin{array}{l}\mathrm{uk} / \mathrm{aku} \\
\mathrm{uku}\end{array}$ & $\mathrm{kw}$ & $\begin{array}{l}\mathrm{kw}+\mathrm{am}= \\
\mathrm{kwam}\end{array}$ \\
\hline $\begin{array}{l}\text { phakathi (between), phandle (outside); phantsi (down); } \\
\text { phezulu (high); phambi (prior/ pre); phambili (forward/ in } \\
\text { front) }\end{array}$ & $\begin{array}{c}\text { pha/ } \\
\text { ph }\end{array}$ & $\mathrm{kw}$ & $\begin{array}{l}\mathrm{kw}+\mathrm{a}+\mathrm{m}= \\
\quad \mathrm{kwam}\end{array}$ \\
\hline
\end{tabular}

